\title{
La educación física en la ciudad de Chihuahua 1900-1950
}

\author{
Physical education in the city of Chihuahua \\ $1900-1950$
}

\author{
Blanca Estela Chávez Díaz \\ Centro de Investigación y Docencia \\ bka.niuji@hotmail.com \\ Federico J. Mancera-Valencia \\ Centro de Investigación y Docencia \\ CA. Desarrollo y Gestión Intercultural en Educación \\ Geógrafo, Maestro en Educación y Doctor en Pedagogía Crítica \\ federico.mancera@cid.edu.mx \\ Lilia Rey Chávez \\ Centro de Investigación y Docencia \\ CA. Desarrollo y Gestión Intercultural en Educación \\ Maestra en Educación \\ lilia.rey@cid.edu.mx
}

Resumen

El origen de la Educación Física en Chihuahua, como educación pública está vinculado a la construcción del Estadio Olímpico de la ciudad deportiva de la Ciudad de Chihuahua en la década de los años 40's del siglo pasado. El diseño arquitectónico es correspondiente al proyecto de modernidad que esta ciudad del desierto se planteaba. La educación física formal se vio favorecida por este discurso arquitectónico, sumándose diversas ideas pedagógicas y procesos socioeconómicos y culturales posrevolucionarios como la educación socialista. Se resaltan los enfoques y políticas educativas en México desde el siglo XX hasta el año 2009. Se identifican al Instituto Científico y Literario, la Universidad Autónoma de Chihuahua y la primera escuela de Educación Física en el Estado.

\section{Palabras clave}

Educación física, historia cultural.

\begin{abstract}
The origin of Physical Education in Chihuahua, as public education is linked to Chihuahua's sport city Olympic Stadium built in last century's 40s decade. The architectural design corresponds to the project of modernity that this desert city pictured. Formal physical education was favored by this architectural discourse, adding various pedagogical ideas and post-revolutionary socio-economic and cultural processes such as socialist education. Educational approaches and policies are
\end{abstract}


highlighted in Mexico from the 20th century up to the year 2009. The Scientific and Literary Institute, the Autonomous University of Chihuahua and the first school of Physical Education in the State are identified.

\section{Keywords}

Physical education, cultural history.

\section{Antecedentes y Justificación}

Este trabajo es parte de la tesis de grado del programa de Maestría en Educación del Centro de Investigación y Docencia (CID), en el marco del proyecto de investigación "Patrimonio Cultural y Educación". Esta tesis se basa en el nacimiento oficial de la educación física en México, en el estado y en la ciudad de Chihuahua, su crecimiento y desarrollo y la construcción del Estadio Olímpico de la ciudad Deportiva como parte de la transformación moderna de una ciudad del desierto mexicano.

\section{Preguntas de investigación y objetivos}

Las preguntas que guiaron la investigación fueron: ¿Qué se ha hecho en el campo de la historia de la Educación Física en Chihuahua en la década de 1940-1950? ¿Cuál fue el impacto general del Estadio de la ciudad deportiva, en la sociedad y en la Educación Física de Chihuahua? ¿Cuál fue la importancia de la ciudad deportiva y el estadio para el desarrollo de la Educación Física para el marco de la profesión profesional? ¿Cuáles fueron los impactos en docencia y la Educación Física (formal e informal) de la ciudad deportiva y el estadio?

De lo anterior surge el objetivo general: analizar y comprender la historia de la educación física, su vinculación con el Estadio Olímpico, su papel social, educativo y su impacto sociocultural. Así en este trabajo se pretende dar a conocer y comprender los antecedentes y la información que se encuentra dispersa a nivel estatal para ponderar los momentos históricospedagógicos en los cuales se desarrolla este tipo de educación

\section{Estrategias metodológicas}

La investigación es de corte histórico, por lo que las metodologías desarrolladas se encuentran la identificación, clasificación y el análisis de las fuentes primarias y secundarias. Se realizó investigación documental de archivos, se clasificó, se redactó en términos descriptivos, se hizo el análisis de la utilización de categorías, como el contexto de la modernidad impactando en el desarrollo urbano, en la educación superior y en el ámbito de la educación física. Se realizaron visitas a bibliotecas $y$ sus colecciones especiales, archivos históricos, particulares, y entrevistas de tradición oral.

\section{Consideraciones teóricas para la historia cultural de la educación física}

La historia cultural de la educación formal así como el de la educación física (EF), no es solo un proceso derivado de la necesidad de la educación formal, ni tampoco un proceso que se gestara por decisiones de políticas educativas. Como todo proceso educativo, esta nace de las particularidades y de las necesidades que se gestan en las distintas culturas y sociedades, con el fin de dar continuidad a su reproducción sociocultural, su continuidad histórica y económica. Las dinámicas educativas son parte y producto sociocultural de sus contextos. Por eso el interés por comprender la historia de la EF en Chihuahua, responde a la perspectiva historiográfica, como parte de la ruptura de hacer historia fundada en criterios universalistas, como es el carácter que impulsó la historia central, universal y euronorteamericana. 


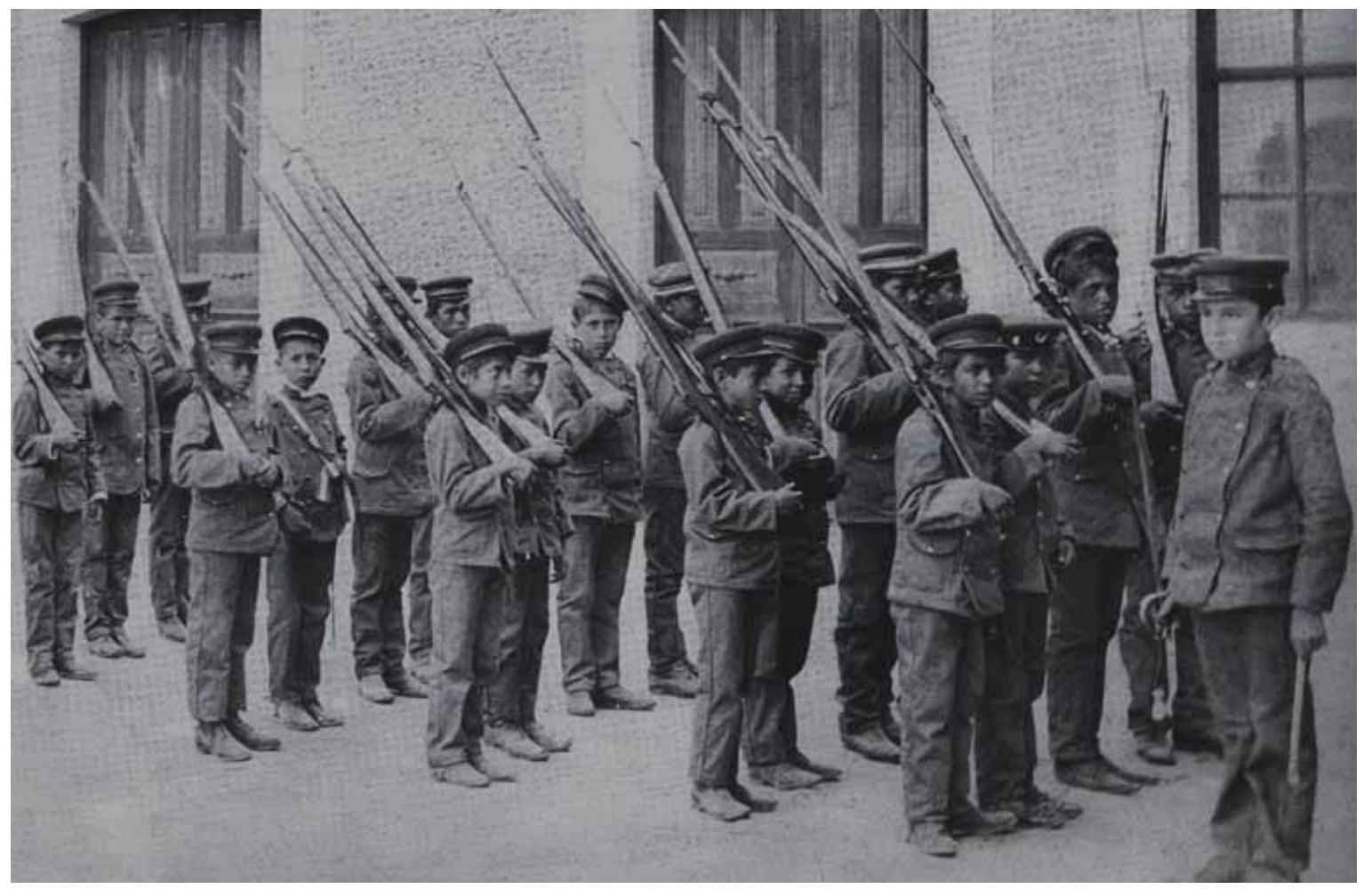

Imagen 1. Niños chihuahuenses haciendo ejercicios con rifles auténticos.

Fuente: Archivo Particular Jesús Vargas Valdés. (1890-1910).

La historia cultural material y la de los sentimientos y lo imaginario, así como el de las representaciones e imágenes mentales la de la cultura élite o de los grandes pensadoreshistoria intelectual en sentido estricto- y el de la cultura popular, de la los sistemas de significados compartidos- en el sentido geetzianou otros objetos culturales producto de esa misma mente, y entre ellos (...), el lenguaje $\mathrm{y}$ las transformaciones discursivas creadoras de sujetos y realidades sociales. Todo ello además no desde una perspectiva fragmentada sino conectada e integrada (Viñao; 2001: pag: 141)

No solo es una historia simple de la educación, aquella que la oficialidad reconoce, o bien que la propia investigación educativa neopositivista desdeña; es la comprensión íntima y social en que se constituyen y enlazan en diferentes procesos culturales, económicos, políticos y ambientales para dar sentido a la gestión de procesos educativos específicos como es el caso de la Educación Física. En ese sentido no podemos dejar de lado el análisis de la vinculación gestada entre el patrimonio cultural y la educación ManceraValencia (2012, pag. 35-36) comenta que en el patrimonio cultural tangible de índole educativo, se puede identificar:

a) Los equipamientos escolares,

b) Los archivos históricos y bibliotecas escolares

c) El Patrimonio mueble.

También menciona otros, como procesos sociopolíticos, y socioculturales que sin ser propiamente patrimoniales gestados en la educación, posibilitan la apropiación y enajenación de los procesos históricos educativos, ya que se derivan de:

a) Procesos socioeconómicos indirectos. Actividades que se gestaron en 
relación a la presencia escolar: tiendas y papelerías, servicio de alimentación y hospedaje para estudiantes y docentes, desarrollo comercial, gestión de nuevos equipamientos (vivienda, salud, comunicaciones, etc.), servicios y nuevos empleos, o bien;

b) Cambios sociales, comunitarios y políticos indirectos. Se refiere al desarrollo de vandalismo y faltas administrativas por alumnos o docentes, raptos con intenciones lascivas, etc., movimientos estudiantiles, nuevos liderazgos y cacicazgos, cambios en la correlación de fuerzas partidistas derivadas por la presencia gremial-sindical del SNTE, nuevos procesos políticos locales y regionales, etc.(2012: P: 38-39)

En este marco es como se ubica el desarrollo de la EF en Chihuahua, que se impulsa con diferentes procesos sociales y culturales vinculados al desarrollo moderno de la ciudad de Chihuahua.

\section{Análisis y resultados: EF en México y en Chihuahua}

La EF a principios del siglo $X X$.

El primer maestro de EF en la República Mexicana fue Manuel Velázquez Andrade a principios del siglo XX. Formado en San Luis Missuri y Boston en los EUA. Para después trasladarse a Europa en donde terminaría de prepararse. A su regreso a México ofrece las primeras estrategias

pedagógicas para la Educación Física en
México (Chávez, 2012: P: 70). Estos se verán reflejados en los planes de estudio del siglo XX de educación primaria. En la primera década del siglo XX solo existían 16 maestros que quienes impartían la asignatura de "Gimnasia". También los médicos s sumaron a la EF, pero principalmente vinculados a la "salud física" actividad que solo se desarrollaba en escuelas superiores. (Chávez, 2012: P: 43)

A nivel nacional durante las dos primeras décadas del siglo $\mathrm{XX}$, prácticamente sólo existían maestros de grupo de educación elemental, maestros "empíricos" que solo sabían leer, escribir y contar; estos eran los que acudían a las academias que tenían como objetivo: "Uniformar la enseñanza de todas las escuelas porque así lo exigían los adelantos modernos de formar maestros teóricoprácticos" así lo señala (Meneses, 1983, pag: 363)

A nivel central de la república mexicana, la EF se le daba mayor énfasis a la gimnasia correctiva, gimnasia médica, gimnasia de aplicación, gimnasia atlética,

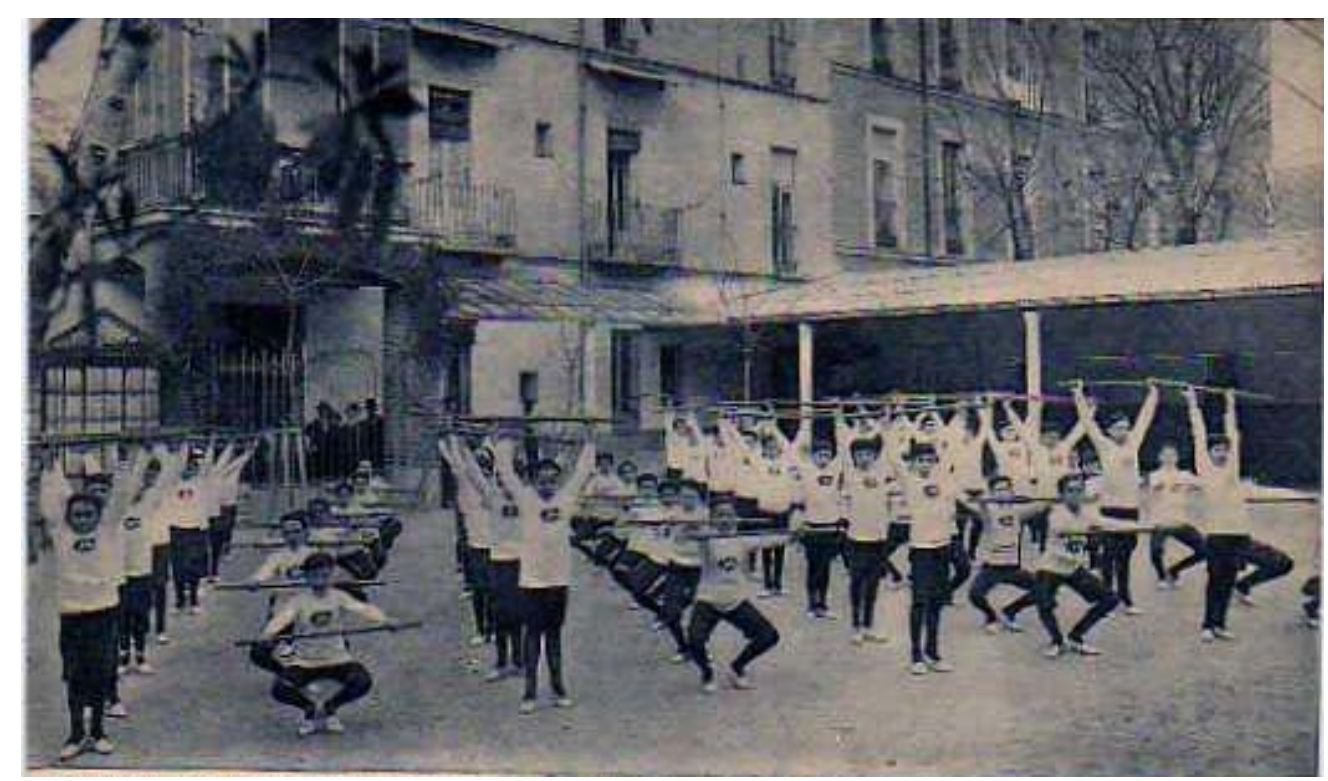

Imagen 2. (Gimnasia Sueca): Aquí se aprecia a los alumnos del colegio de Nuestra Señora del Pilar de Madrid España, realizando movimientos acordes a la gimnasia sueca de esa época. Fuente: www.todocolección.net 
antropometría, juegos gimnásticos, juegos deportivos, juegos atléticos e higiene aplicada al desarrollo físico (Chávez 2012 P: 46).

No obstante, en los estados de la república fue distinto (Ver cuadro 1). El primer maestro de educación física registrado en 1905, en los archivos del Instituto Científico y Literario de Chihuahua fue Felipe Llera. Para ese entonces la EF, en general se impartía de manera formal en el citado instituto. La EF que se impartía era de dos tipos:

a) La militar. A los niños se les preparaba para la guerra, no se olvida que recién terminado estaba la guerra contra los apaches (1890), gran parte de la población poseía armas y era muy común generar conocimiento al respecto. (Ver imagen 1)

b) La gimnasia sueca, para ambos géneros. Así los demuestra el Álbum de la Enseñanza de Educación editada en 1909, donde se ejemplifica con imágenes la educación de las niñas y los niños. La gimnasia sueca, fue un método creado por Pier Henrich Ling (1776-1839) que se caracteriza por una concepción anatómica, biológica y correctiva, que fueron incorporadas al sistema educativo europeo $y$ norteamericano a finales del siglo XIX y principios del XX. La cercanía con los Norteamérica permitió a llegada de este tipo de EF, que para los 1920 al 1933 las clases de Educación Física tomaron otro rumbo acercándose más a lo deportivo implementándose así las técnicas del deporte, la gimnasia y la recreación para niños y jóvenes, programas derivados de la Asociación de Jóvenes Cristianos (YMCA) (ver imagen 2)
La EF en la posrevolución y la entrada a la modernización de Chihuahua.

En el período de la posrevolución se inicia nuevas esperanzas y expectativas, el discurso del desarrollo y la modernidad entraban con gran fuerza en las políticas educativas. Y sin duda las Misiones culturales (1924) representaron uno de los modelos educativos y culturales más representativos de la época.

A Chihuahua en 1928, llega como maestro de Educación Física Roberto Braulio Saldívar, egresado del Instituto Técnico en Montevideo Uruguay, el impulsa el trabajo de la EF apoyando las Misiones Culturales. Con el Cardenismo se fortalece la EF en las Misiones Culturales y toma así la formalidad en la educación.

No obstante, la actividad física identificada como deporte sólo se desarrollaba en los ambientes de las clases sociales altas. La elite regional como las familias Creel, Terrazas, Zuluaga, practicaban el deporte "europeo" como la hípica, el atletismo y el boxeo entre otros. (Rodríguez, 2010) También, se ejercitaba la gimnasia, el tiro al blanco, el esgrima, la lucha libre, la acrobacia circense, el patinaje sobre ruedas, el ciclismo, el boliche, corridas de toros, así como el frontón vasco. Fueron, en suma, las principales actividades de cultura física, las que perduran durante el porfiriato y las posrevolución. (Rodríguez, 2010; Bezzley; $\mathrm{s} / \mathrm{f}:)$.

El boliche, era muy preciado, en la exhacienda Quinta Carolina existe un espacio en el conjunto arquitectónico utilizado para ese fin. Su práctica solo era para las clases sociales altas. Incluso es hasta el siglo XX en la década de los 50's se practicaba de manera exclusiva en la ciudad de Chihuahua.

La actividad hípica, a pesar de las dificultades de contar con ganado caballar, su presencia para toda la actividad ganadera resultaba importante debido al trabajo de los caporales y así mismo en el rodeo: 


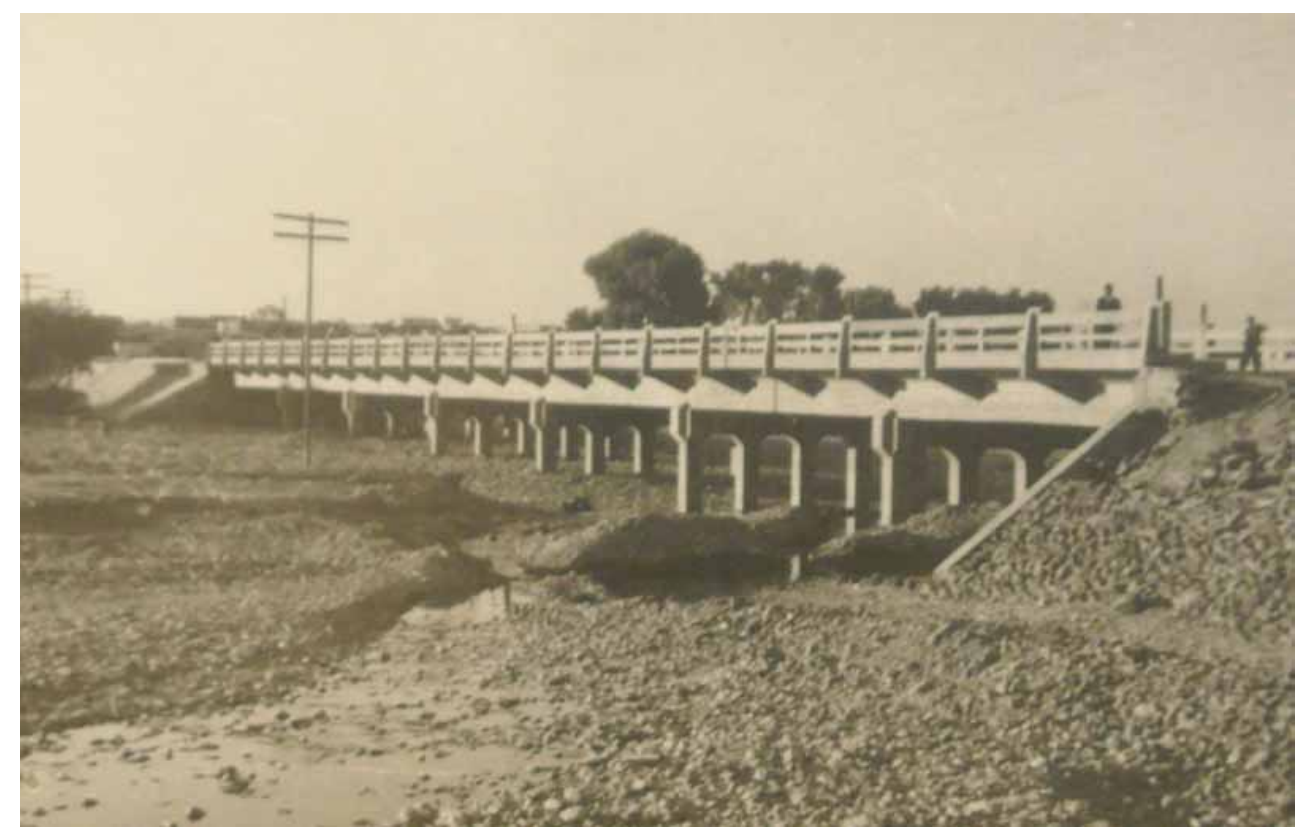

Imagen 3. Obra en construcción del puente del Río Chuvíscar a principios del año 1940.

Fuente: Archivo Particular Mario Trillo.

de trabajador: el vaquero. Esta persona era la encargada de movilizar a los animales para lograr un mejor aprovechamiento; sus actividades incluían la movilización de los semovientes en busca de los mejores pastos y agua en casos de sequía, herrar los animales en los rodeos y hacer la separación de los animales a venderse (Hernández, 2011 P: 80)

De estas actividades surgen dos actividades deportivas populares: los jaripeos y las (...) la labor que se desarrolla con la ganadería implicaba un tipo preciso carreras de caballos, practicadas en las rancherías del semidesierto de Chihuahua.

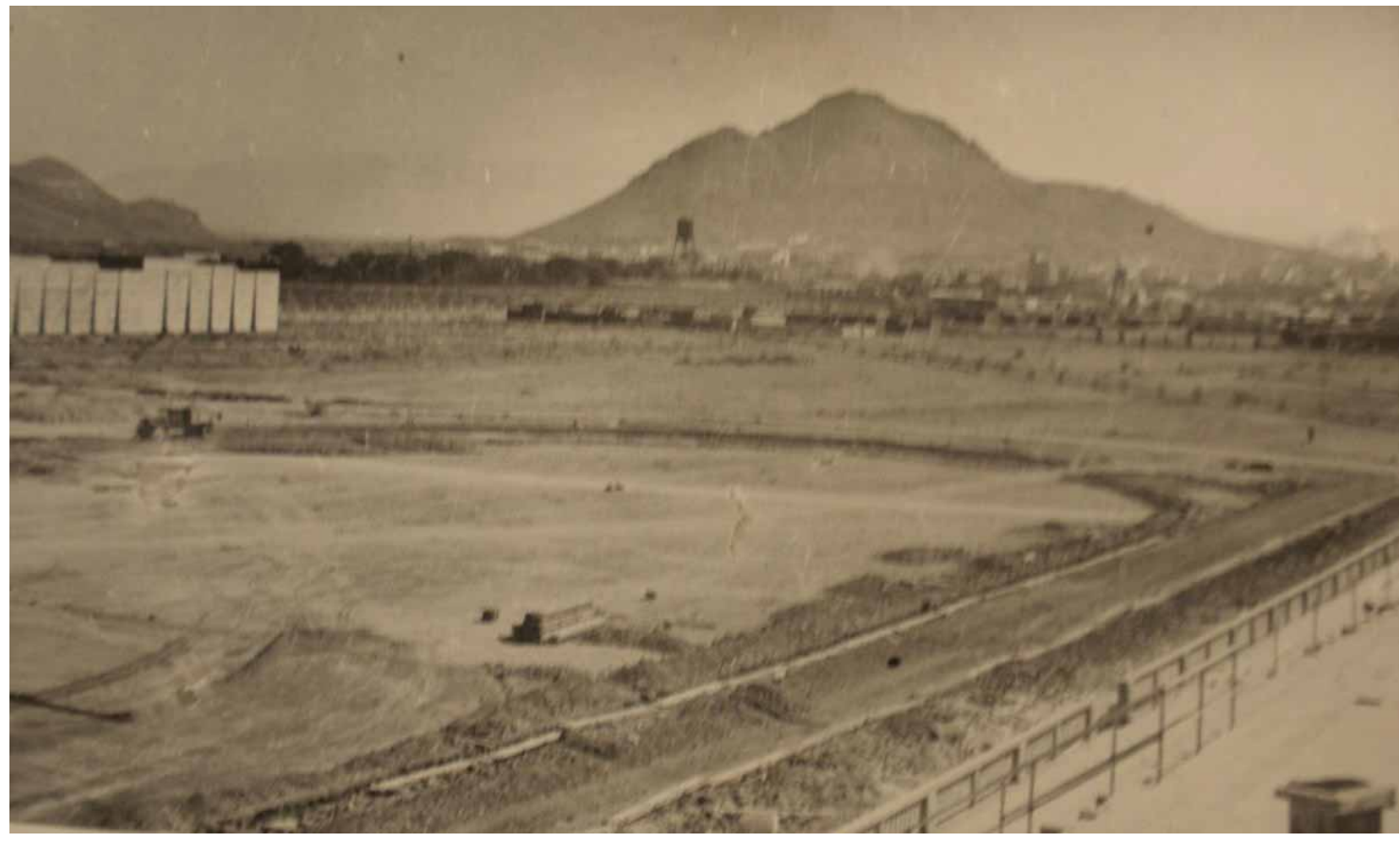

Imagen 4. En la imagen de arriba se observa la vista aérea del terreno virgen, a lo lejos se observa el Cerro Coronel. Fuente: $A H A C H$. 
Se considera que hay dos momentos históricos que posibilitan el desarrollo de la EF: a) el Cardenismo (1934-1940) con su política social, los movimientos obreros, las corrientes pedagógicas socialistas influyeron en las demandas sociales para la educación social y popular (creación del Consejo de Cultura Física); b) los proyectos de modernidad surgidos en los 40 y 50's., posibilitaron el discurso del progreso reflejados en la urbanización y la industrialización. En este contexto de 20 años (1934-1954) (ver Cuadro 1) la EF en Chihuahua se socializo y popularizo, debido:

1ero. La socialización de la EF posibilito la popularización de los deportes, como una actividad social y por tanto la demanda por espacio públicos.

2‥ La EF obtuvo una fundamentación científica dentro de la educación formal para crear un desarrollo anatomofisiológico del sujeto. (Boatou, 2008)

3ㅇ․ El crecimiento de la ciudad de Chihuahua hacia el norte de la ciudad y la planificación de dos grandes equipamientos $\mathrm{y}$ proyectos sociales: la construcción del Estadio Olímpico y la Ciudad Deportiva (1947) y Universidad

Autónoma

Chihuahua (UACH) (1954), sucesos arquitectónicos $\mathrm{y}$ socioeducativos $\mathrm{y}$ culturales

importantes para la ciudad en los años de 40's y 50's.

El conjunto de estos procesos trajo cambios sociales, en la educación y el deporte, se transformaron los hábitos del uso del tiempo libre, la política social y la imagen urbana de la ciudad de Chihuahua.

\section{La EF y la Modernidad en Chihuahua.}

A nivel nacional, en 1940, se crea la Dirección Nacional de Educación Física donde se desarrolla el primer Programa de Educación Física que comprendían 4 aspectos: Gimnasia, Juegos Recreativos, Educación Deportiva e Instrucción Militar. Aun la presencia militar y los deportes formaban parte de un grupo y clase social, la cual fue cambiando a una más social y popular.

La capital del estado de Chihuahua, crece y se expande hacia el norte por lo que exige de nueva infraestructura de comunicación y trasporte. El concreto hace su aparición en puentes y en toda la arquitectura. (Imagen 3)

Por otra parte, al norte de la Ciudad de Chihuahua, en septiembre 26 de 1946, inaugura el Presidente de la República Miguel 
Alemán Valdés el Estadio de la ciudad Deportiva. En un espacio donde aún el desierto ocupaba terreno. Imágenes 4 y 5 )

El Estadio Olímpico era poco considerado para las prácticas populares deportivas, el pueblo prefería la corrida de toros. (Imagen 6).

En 1948 El presidente Miguel Alemán decreta la creación del Instituto Federal de Capacitación del Magisterio en Educación Física para quienes se dedicaban a esta profesión y que laboraban en el sistema federal, estatal, municipal o particular, con el fin de profesionalizar este personal con la obtención de un título.
Por otra parte, con la creación de la UACH (1954), se van gestando la necesidad de crear profesionistas en educación física. Así en 1956, nace el acuerdo de la creación de la Escuela de Educación Física (EEF) en Chihuahua y el 19 de abril, de ese mismo año, se abren las puertas de esta Escuela en aulas de la antigua Escuela de Ganadería con un enfoque pre-militar a nivel técnico. En 1959, se define el primer director de Educación Física profesor Roberto Braulio Saldivar, elegido por el Gobernador de una terna integrada por Roberto Zueck Ruffini y Rafael Revilla.

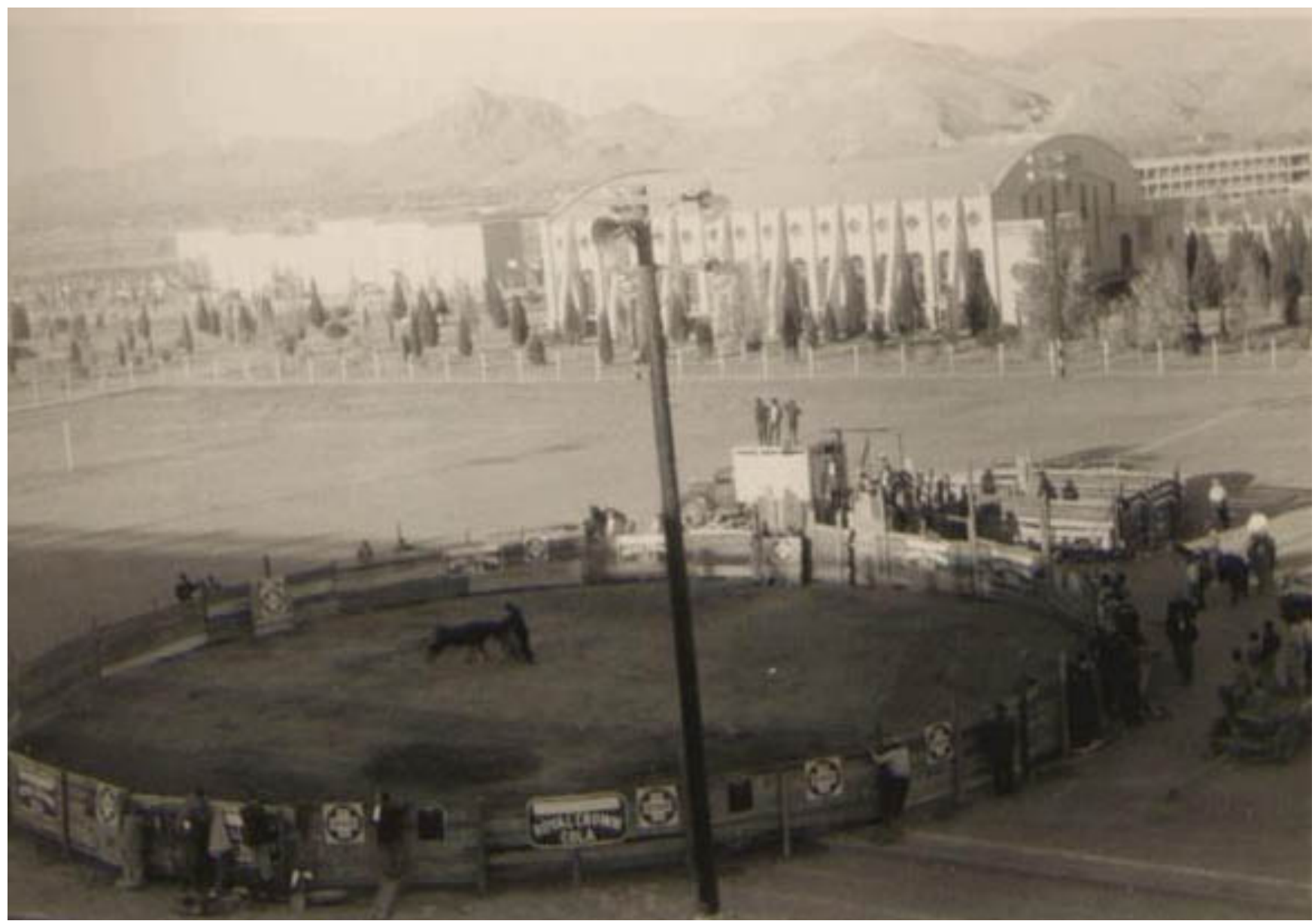

Imagen 6. Evento de corrida de toros en el estadio de la Ciudad Deportiva, uno de los multiusos que se le ha dado a este recinto a través de los años foto del mes de abril de 1955; el estadio solo estaba cercado con postes y alambrado.

Fuente: Archivo Particular Mario Trillo. 
En 1960 es reelegido Roberto Braulio Saldívar, frente a los aspirantes Hipólito Vela y Arturo Zueck Ruffini

El secretario de la EEF fue el profesor Arturo Zueck, en el su primera generación se inscribieron 19 maestros de educación básica o elemental, graduándose solo 16; los catedráticos eran: Pedro Barba, Ramón Carmona, Hipólito Vela, Alberto Romero Pérez, María Elena Campos, José Spíndola, José María Sánchez.
Las clases prácticas se impartían en el Gimnasio Rodrigo M. Quevedo, en el Gimnasio Revilla, en el Estadio de la Ciudad Deportiva y en la Alberca del San Antonio.

Para elaborar el Plan de Estudios, hubo que consultar los programas académicos de otras instituciones educativas con experiencia en este campo, como la Escuela de Educación Física de Montevideo, Uruguay, la experiencia de Y.M.C.A., de la Escuela Nacional de Educación Física en México. (Hernández, (1999),(2004), (2002).

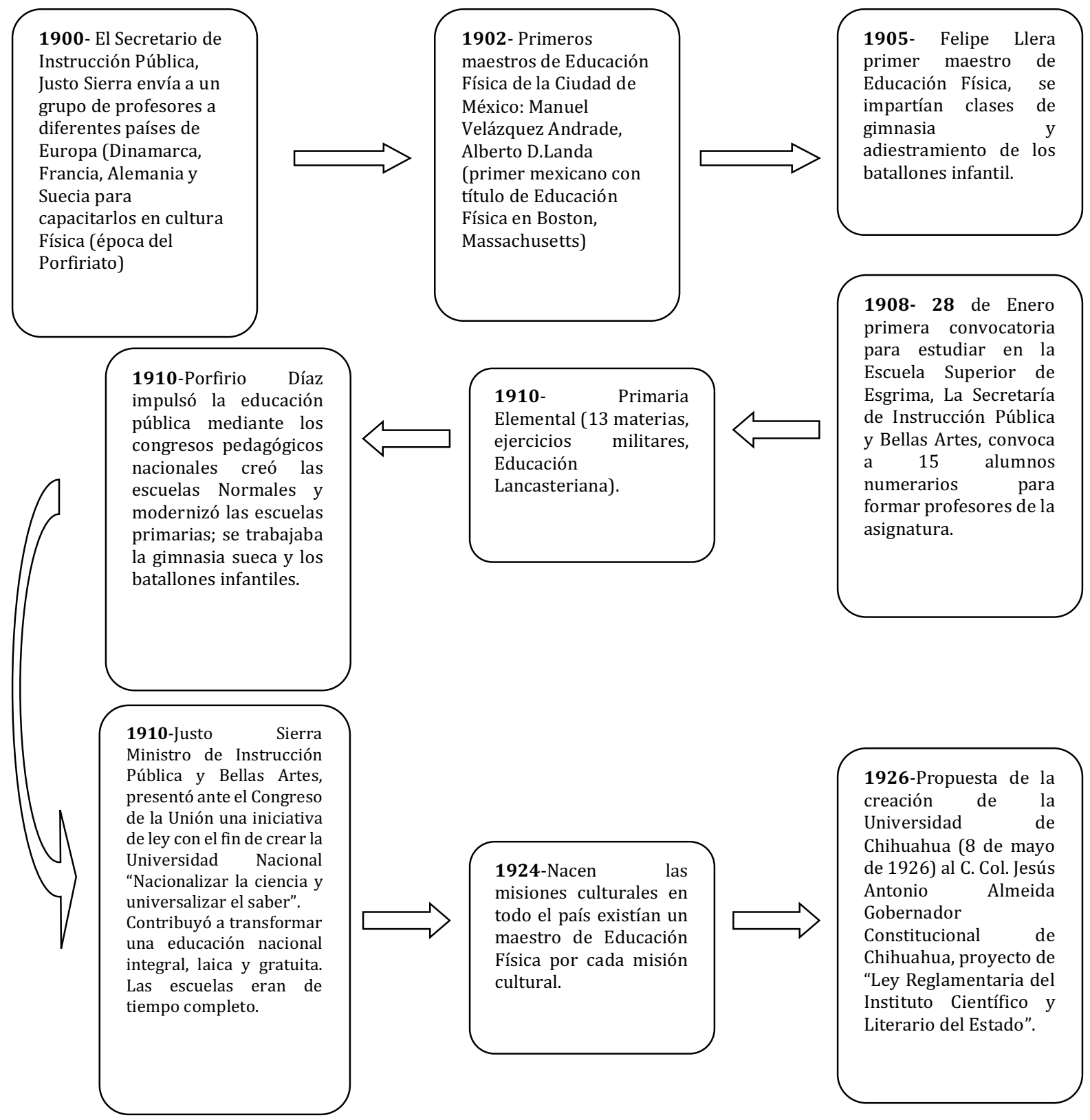

La educación física en la ciudad de Chihuahua 1900-1950 


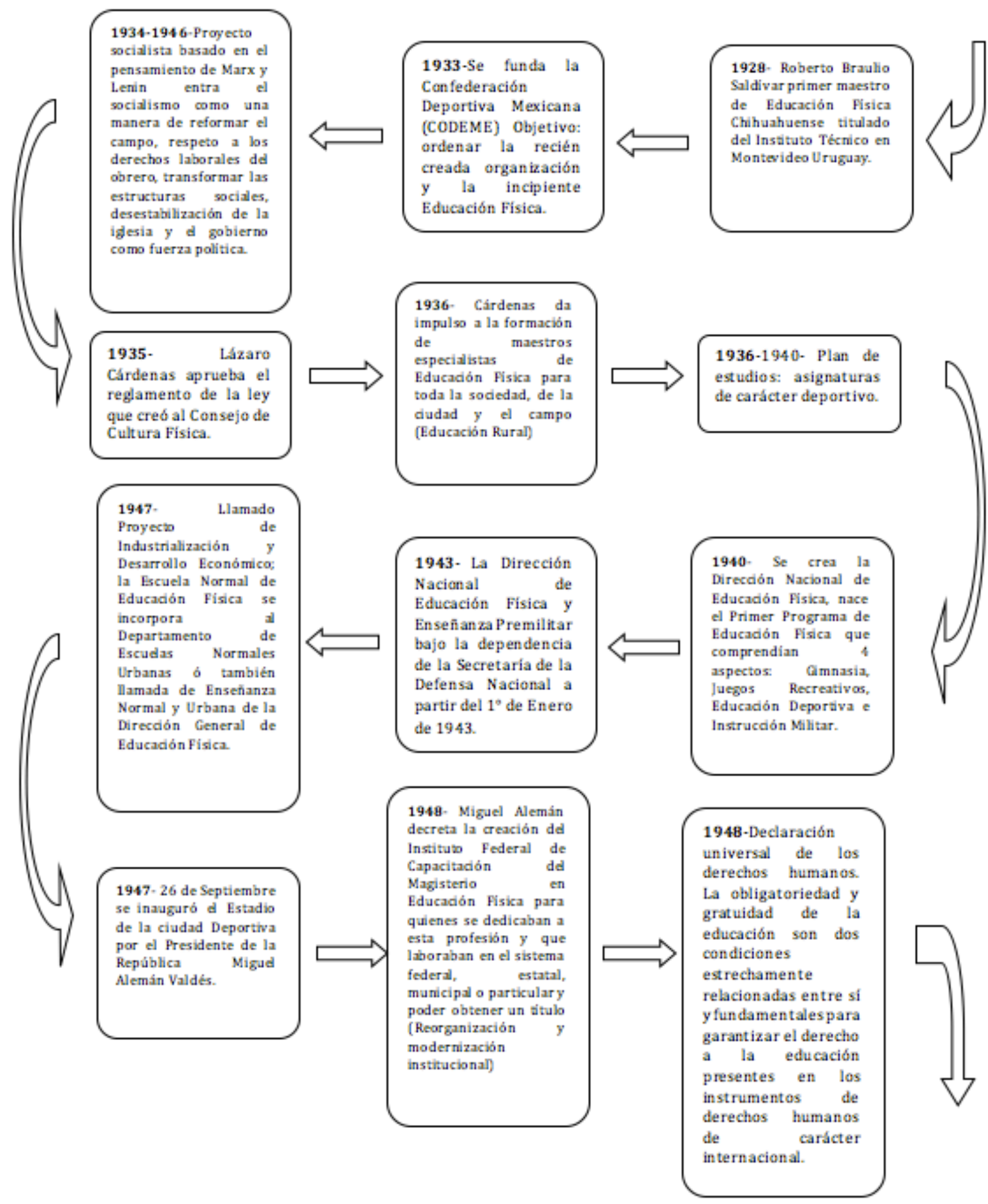




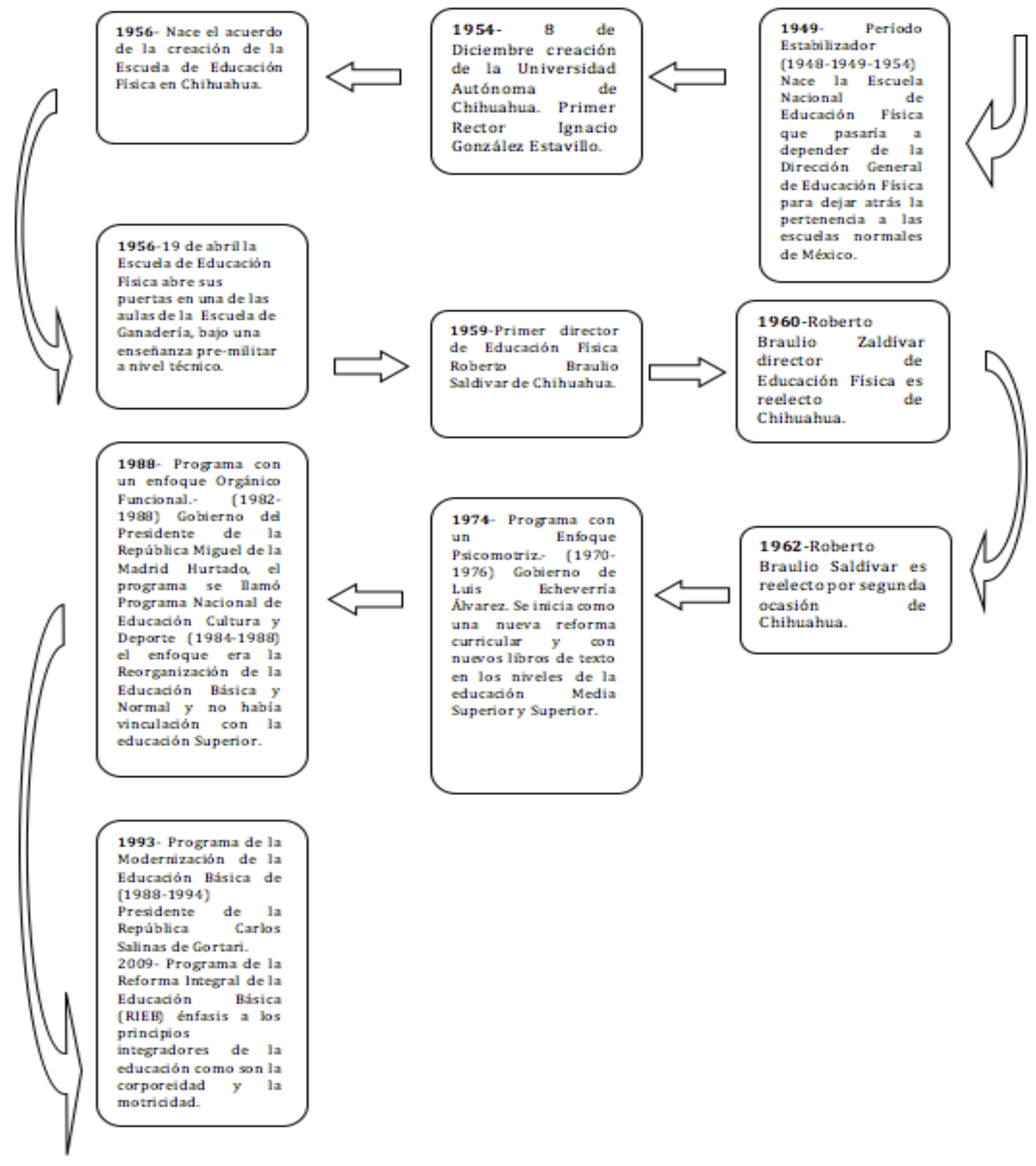

Cuadro 1. Cronología histórica de la educación física. 


\section{A manera de conclusión}

física permitió comprender los procesos paralelos de orden histórico social y político que contribuyeron al desarrollo de la educación física y, así mismo, del deporte en Chihuahua, que por muchos años fueron reconocidos por su liderazgo a nivel nacional e internacional.

\section{Referencias}

Boatou, Jorge (2008). "Gimnasia Sueca”, en Historia y Etnografía de la Educación Física. Extraído de: http://historiaefi.blogspot.mx/2008/ 06/gimnasia-sueca.html.

Chávez López, Ricardo (2012) Historia de la Educación Física en México, Trillas P: 43-70.

Hernández Orozco, Guillermo (1999) La Universidad Autónoma de Chihuahua 1850-1900. Textos Universitarios P: $250-251$.

Hernández Orozco, Guillermo. (2004) La Universidad Autónoma de Chihuahua: 1850-1900. Textos Universitarios. Universidad Autónoma de Chihuahua P: 295
Hernández Orozco, Guillermo. (2002) Síntesis Histórica de la Universidad Autónoma de Chihuahua 1954-2002 P: 14 -82.

Mancera-Valencia, Federico J. 2011. "El patrimonio cultural escolar en Chihuahua: consideraciones para su estudio", en: "Revista de Investigación Educativa REDIECH. Año 1. No. 2. AbrilSeptiembre. Chihuahua, Chih. México., P: 45.

Mancera-Valencia, Federico J. (Coord.) (2012) Patrimonio Cultural Escolar de Chihuahua. Instituto Chihuahuense de la Cultura, CONACULTA, CID. Chihuahua, México. pp. 23-264.

Viñao Frago, Antonio. "Historia de la educación e historia cultural. Posibilidades, problemas, cuestiones", en María Esther Aguirre Lora. Rostros históricos de la educación. Miradas, estilos, recuerdos. CESU. UNAM. FCE México, D.F. P: 140-164. Y en: Revista Brasileña de Educación. Sep. Dic. No. 0. P: 63-62. Extraído de: http://189.1.169.50/rbe/rbedigital/. 